06;15

\title{
Получение наноразмерного детонационного углерода на импульсном газодетонационном аппарате
}

\author{
(C) А.А. Штерцер, В.Ю. Ульяницкий, И.С. Батраев, Д.К. Рыбин
}

Институт гидродинамики им. М.А. Лаврентьева СО РАН, Новосибирск, Россия

E-mail: asterzer@mail.ru

Поступило в Редакцию 26 декабря 2017 г.

Путем сжигания или термического разложения углеводородных топлив получают различные формы углерода, при этом детонационный способ сжигания представляет отдельный интерес, поскольку получаемый наноуглерод по свойствам отличается от продуктов, изготавливаемых другими способами. Новые возможности для производства наноуглерода открывает импульсный газодетонационный аппарат, созданный на базе установки детонационного напыления CCDS2000. В аппарате используется проточная подача газов в реактор при атмосферном давлении, что обеспечивает высокую производительность и безопасность этого способа. С помощью детонации переобогащенных ацетиленокислородных смесей получен наноразмерный детонационный углерод с различной морфологией частиц, зависящей от соотношения компонентов в смеси.

DOI: 10.21883/PJTF.2018.09.46067.17165

Технический углерод (сажа) широко применяется при изготовлении различных изделий: от автомобильных шин до электронных устройств и источников питания. Традиционные способы получения технического углерода в большинстве основаны на горении или термическом разложении углеводородов $[1,2]$. При этом одним из наиболее ценных продуктов является углерод, получаемый из ацетилена, - ацетиленовая сажа (acetylene black). В частности, сажа, производимая компанией Denka (Япония), полученная путем термического разложения ацетилена, характеризуется средним размером частиц $d=35 \mathrm{~nm}$, удельной поверхностью $S=68 \mathrm{~m}^{2} / \mathrm{g}$ и плотностью $\rho=0.04 \mathrm{~g} / \mathrm{cm}^{3}$, а ацетиленовая сажа с высокой электропроводностью производства компании Soltex 
(США) имеет $d=25-45 \mathrm{~nm}, S=100-120 \mathrm{~m}^{2} / \mathrm{g}$ и $\rho=0.05-0.09 \mathrm{~g} / \mathrm{cm}^{3}$. Кроме традиционных „печных“ способов получения технического углерода существуют также методы, основанные на взрывном разложении ацетилена $[3,4]$, когда этот газ (обычно под давлением существенно выше атмосферного) подается в реактор и инициируется детонация. Отметим, что для возбуждения детонационного режима разложения ацетилена без добавок окислителя при атмосферном давлении диаметр реактора (труба, заполняемая газом) должен быть не менее $100 \mathrm{~mm}$ [5]. В [6] предложен способ получения углерода путем детонации смесей ацетилена с кислородом при атмосферном давлении. По утверждению авторов порошок состоит из частиц графена (graphene particles). В этом способе, как и в $[2,3]$, реактор заполняется газом, плотно закрывается и производится инициирование детонации от свечи зажигания. После этого реактор открывают и извлекают полученный продукт. В детонирующей смеси $\mathrm{C}_{2} \mathrm{H}_{2}+k \mathrm{O}_{2}$ содержание кислорода варьировалось от $k=0.4$ до 0.8 . По утверждению авторов производительность способа при объеме реактора (цилиндрическая камера) 16.61 достигает $300 \mathrm{~g}$ углерода в час. Удельная поверхность $S$ получаемого порошка изменяется от 187 до $23 \mathrm{~m}^{2} / \mathrm{g}$ при изменении $k$ от 0.4 до 0.8 . Углеродные частицы имеют размер $35-55 \mathrm{~nm}$ при $k=0.4$ и 0.5 , растут с увеличением $k$ и достигают $d=250-350 \mathrm{~nm}$ при $k=0.8$. Таким образом, свойства наноуглерода, получаемого различными способами и в различных технологических режимах, значительно различаются.

Задача настоящей работы заключается в разработке производительного и безопасного метода получения детонационного наноуглерода для исследовательских целей и промышленного применения. На базе установки детонационного напыления CCDS2000 [7,8] с учетом первых опытов по получению наноуглерода [9] создан импульсный газодетонационный аппарат (ИГДА), работающий в непрерывном циклическом режиме с автоматическим повторением циклов (рис. 1). Рабочие газы (топливо, окислитель) подаются из баллонов в газораспределительный механизм 3. В каждом цикле по сигналам с компьютера 6 происходит открытие клапанов газораспределителя и подача газов - компонентов детонирующей смеси - в камеру смешения-зажигания 1 и далее уже готовой смеси 5 в ствол 2 , играющий роль реактора. Затем от свечи зажигания 7 производится инициирование детонации, и цикл заканчивается прохождением детонационного фронта по стволу и выбросом газообразных продуктов детонации и твердофазного углерода

Письма в ЖТФ, 2018, том 44, вып. 9 


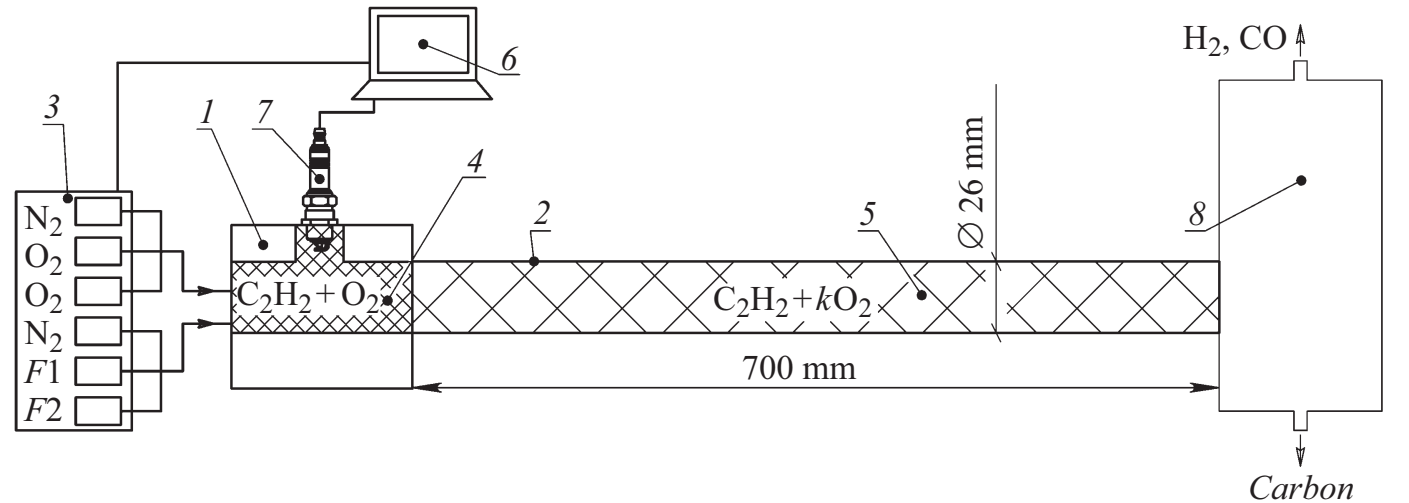

Рис. 1. Импульсный газодетонационный аппарат: 1 - камера смешения-зажигания, $2-$ водоохлаждаемый ствол, 3 - газораспределитель, 4 - заряд-бустер, 5 - основной заряд детонирующей газовой смеси, 6 - управляющий компьютер, 7 - свеча зажигания, 8 - коллектор для сбора продукта. Клапаны подачи газов из газораспределителя: $F 1$ и $F 2$ - топливные, $\mathrm{O}_{2}$ - кислорода, $\mathrm{N}_{2}-$ азота. 
Зависимость производительности ИГДА $Q$ и плотности НДУ $\rho$ от состава ацетиленокислородной смеси $(k-$ отношение числа атомов кислорода к числу атомов углерода, $\eta$ - молярное содержание кислорода)

\begin{tabular}{c|r|c|c}
\hline$k$ & $\eta, \%$ & $Q, \mathrm{~kg} / \mathrm{h}$ & $\rho, \mathrm{g} / \mathrm{cm}^{3}$ \\
\hline 0.11 & 9.9 & 1.80 & 0.013 \\
0.18 & 15.0 & 2.25 & 0.014 \\
0.26 & 20.6 & 2.70 & 0.020 \\
0.30 & 23.1 & 1.80 & 0.041 \\
0.42 & 29.6 & 1.26 & 0.055 \\
0.57 & 36.2 & 0.26 & 0.024 \\
0.68 & 40.4 & 0.07 & 0.020
\end{tabular}

в коллектор 8 , откуда осуществляется отвод газообразных продуктов детонации и сбор продукта после серии циклов (выстрелов). При низком содержании кислорода в основной смеси $5(k<0.4)$ энергии разряда автомобильной свечи 7 не хватает для возбуждения в ней детонации. В этом случае в стволе создается двухслойный заряд: после заполнения ствола основной смесью 5 некоторый участок казенной части ствола 2 и камера смешения-зажигания 1 заполняются зарядомбустером 4, представляющим собой легко инициируемую смесь, например $\mathrm{C}_{2} \mathrm{H}_{2}+\mathrm{O}_{2}$ (рис. 1). От описанных выше методов $[3,4,6]$ процесс в ИГДА отличается тем, что подача газов осуществляется в проточном режиме при давлении ацетилена не более $0.14 \mathrm{MPa}$, а в стволе-реакторе давление составляет $0.1 \mathrm{MPa}$, что отвечает требованиям взрывобезопасности, общепринятым для технологий газосварочного производства. В то же время в других „взрывных“ методах, подобных описанным в [2,3], ацетилен подвергается предварительному сжатию до высоких давлений $(0.35 \mathrm{MPa}$ и выше), и к производству должны предьявляться требования по безопасности высшей категории. Проточный режим подачи газов в реактор обеспечивает повышение производительности за счет сокращения времени цикла, поскольку нет необходимости герметично закрывать и после взрыва открывать реактор, так как в ИГДА ствол открыт с одной стороны и выброс продуктов детонации в коллектор 8 (рис. 1) происходит автоматически. Газообразные продукты детонации, в основном $\mathrm{H}_{2}$ и $\mathrm{CO}$, из коллектора уходят в вентиляционную систему,

Письма в ЖТФ, 2018, том 44, вып. 9 

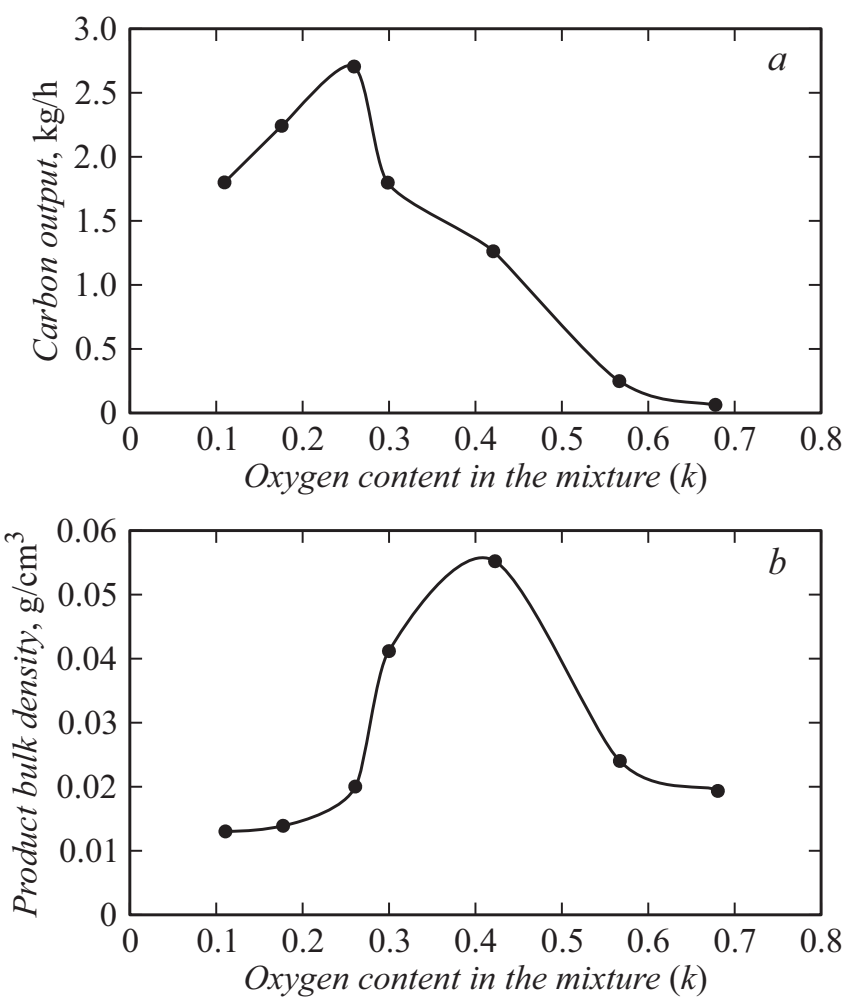

Рис. 2. Зависимость производительности ИГДА $(a)$ и плотности получаемого продукта $(b)$ от $k$ при темпе работы 5 выстрелов в секунду.

a твердофазный продукт - наноразмерный детонационный углерод (НДУ) - накапливается от выстрела к выстрелу.

В экспериментах по получению НДУ применялся ствол ИГДА диаметром $26 \mathrm{~mm}$ и длиной $700 \mathrm{~mm}$, так что объем ствола составлял $372 \mathrm{~cm}^{3}$, что существенно меньше, чем объем реактора в [6]. Использовались переобогащенные ацетиленокислородные смеси $\mathrm{C}_{2} \mathrm{H}_{2}+k \mathrm{O}_{2} \mathrm{c}$ варьированием $k$ от 0.11 до 0.68 , что отвечает примерным содержаниям кислорода 10 и 40\% соответственно. При $k<0.11$ указанная смесь уже не детонирует, а при $k>0.7$ выход твердофазного углерода

Письма в ЖТФ, 2018, том 44, вып. 9 


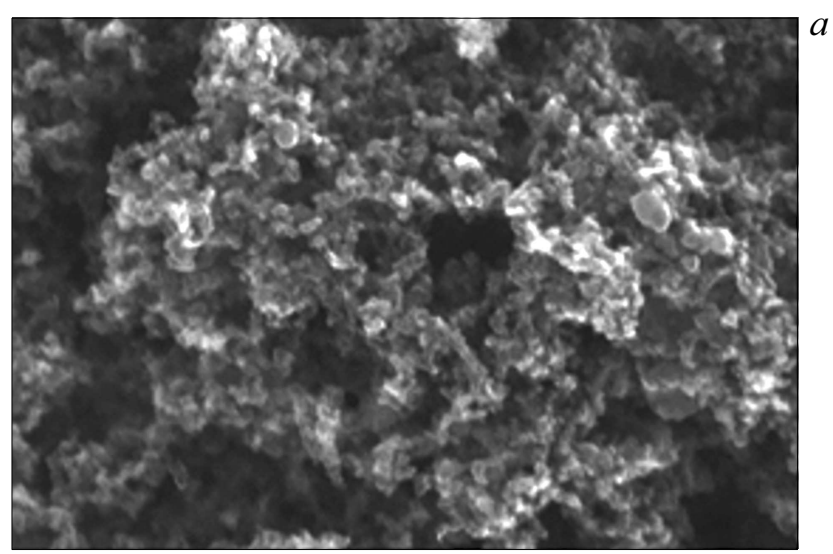

$\stackrel{100 \mathrm{~nm}}{\longmapsto}$

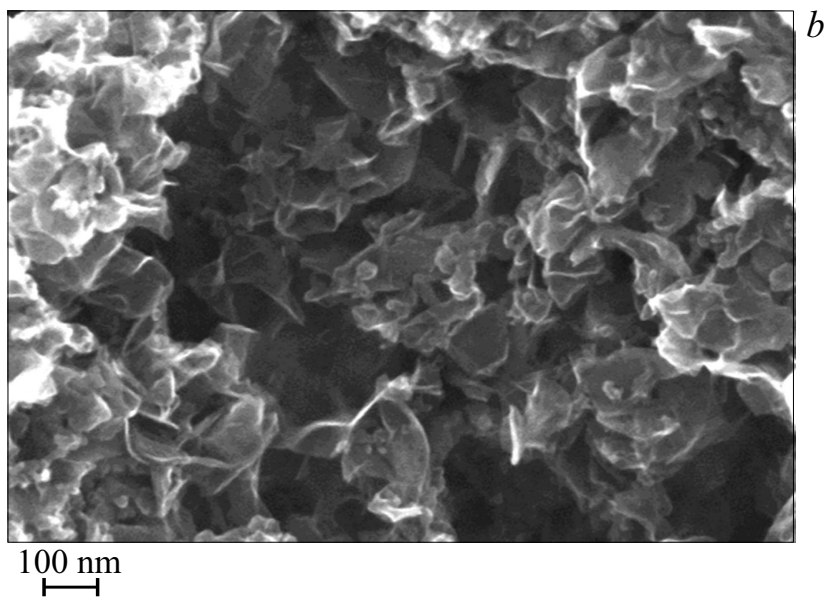

Рис. 3. Морфология частиц НДУ, полученного при $k=0.11(a) 0.68(b)$.

незначителен. При $k \geqslant 1$ кислорода хватает для полного окисления углерода, и он в твердой фазе в продуктах детонации отсутствует. Экспериментальные данные по производительности ИГДА при темпе работы 5 выстрелов в секунду и плотности получаемого НДУ представлены в таблице и на рис. 2 , откуда видно, что зависимость выхода

Письма в ЖТФ, 2018, том 44, вып. 9 
НДУ от $k$ носит немонотонный характер и наблюдается максимум производительности $2.7 \mathrm{~kg} / \mathrm{h}$ при $k=0.26$. Такой результат пока не понятен, поскольку в каждом выстреле объем детонирующей смеси одинаков, а с ростом $k$ уменьшается количество углерода в смеси и увеличивается его окисленная доля. На наш взгляд, данная информация весьма полезна для исследователей, разрабатывающих теоретические модели детонации переобогащенных газовых смесей, когда в продуктах реакции имеется твердофазный углерод. Зависимость плотности НДУ $\rho$ от $k$ также немонотонна, имеется максимум $\rho=0.055 \mathrm{~g} / \mathrm{cm}^{3}$ при $k=0.42$ и минимум $\rho=0.013 \mathrm{~g} / \mathrm{cm}^{3}$ при $k=0.11$. Такое большое различие в плотности может свидетельствовать о различии в морфологии частиц НДУ, получаемого при разном содержании топлива и окислителя в детонирующей смеси. Электронно-микроскопические снимки частиц подтверждают это. Из рис. 3 видно, что частицы углерода, полученного при $k=0.11$, имеют округлую форму и размер в десятки нанометров, а при $k=0.68$ они приобретают форму чешуек размером более $100 \mathrm{~nm}$ и толщиной порядка $10 \mathrm{~nm}$. Учитывая большую разницу в плотности НДУ и продуктов, выпускаемых компаниями Denka и Soltex, можно предположить, что и другие свойства (удельная поверхность, электросопротивление, электрохимические показатели и др.) будут также различаться. В настоящее время проводится всестороннее изучение свойств НДУ для определения областей применения.

Таким образом, разработан новый высокопроизводительный и относительно безопасный метод получения наноразмерного углерода путем детонационного сжигания ацетиленокислородных смесей в импульсном газодетонационном аппарате.

\section{Список литературы}

[1] Мансуров 3.А. // Физика горения и взрыва. 2012. Т. 48. № 5. С. 77-86.

[2] Зуев В.П., Михайлов В.В. Производство сажи. М.: Химия, 1970. 318 с.

[3] Kistiakovsky G.B., Halsey G.D., Malin M.E., Knight H.T. Detonation process of making carbon black. US Patent N 2690960. Oct. 5, 1954.

[4] Кнорре В.Г., Низовщев В.Е., Прядкина Е.А., Сидоров В.Н. Способ получения технического углерода. Патент РФ № 2325413 от 27.05.2008.

[5] Манжалей В.И. // Физика горения и взрыва. 1975. Т. 11. № 1. С. 146-149.

Письма в ЖТФ, 2018, том 44, вып. 9 
[6] Sorensen C., Nepal A., Singh G.P. Process for high-yield production of graphene via detonation of carbon-containing material. US Patent N 9440857. Sept. 13, 2016.

[7] Ульяницкий В.Ю. // Упрочняющие технологии и покрытия. 2013. № 10. C. $36-41$.

[8] Ulianitsky V., Shtertser A., Zlobin S., Smurov I. // J. Thermal Spray Technol. 2011. V. 20. N 4. P. 791-801.

[9] Штериер А.А., Ульяницкий В.Ю., Батраев И.С., Громилов С.А., Окотруб А.В., Сапрыкин А.И. // Журн. структур. химии. 2014. Т. 55. № 5. C. $1031-1034$. 